\title{
Emoticon Symbols Applied for Traffic Signs
}

\author{
Sodikin \\ Universitas Veteran Bangun Nusantara \\ Sukoharjo, Indonesia \\ sodikinusman@yahoo.com
}

\begin{abstract}
Emoticon is the visualization symbols as the representation of emotion and usage in social media cellphone for communication. This article aims to develop the new design of traffic signs by modification emoticon symbol. The traffic signs symbolizing the distracted driver behavior because it is influenced of alcohol, because influenced of reading or text to operate the cell-phone, and distract driver because too much talking, discussing or debate with the other passenger. There are 140 participants explored their capability to understand, notice and memorize the traffic signs, as well as relate those signs to their own driving experiences. The drivers commonly state that emoticon traffic signs are quite easy and enough to understand for the comprehension, quite easy and enough to attract attention for the conspicuity and quite easy and enough to remember for the learnability and the relevance conditions represented that designs are never or sometimes experienced by the drivers. So the emoticon symbols proper to be applied for the traffic signs and it can be understood broadly, mainly by those who are illiterate or problematic in linguistic.
\end{abstract}

Key words: emoticon symbols, design, traffic signs

\section{INTRODUCTION}

The graphics emoticon usage in social network services, blogs, and mobile phone communication illustrate that these graphic emoticons are now evolving into ideographic images as substitutes for words or phrases from accessory markers showing the emotional state of the writer. It will be argued that the behavior of these graphic emoticons will give us valuable insights for implementing a universal auxiliary visual language that will overcome the barrier of language differences. Possible educational applications of the future universal visual language will be also proposed [1].

The emoticon is actually the acronym of an emotional icon. An emoticon is used as the relational icons to express the mood or emotion or to give the sign toward the intention of joking. Some popular emoticons include smiling, blinking, getting angry and frowning. An emoticon is a visualization formed by common flipped typographic symbols as the representation of emotion. It is created as the compensation from the disability in delivering voice message, mimic, or gesture in the written communication. Therefore, it facilitates the combination of both written message and face to face interaction describing what is being symbolized the writer toward the readers [2].

The effectiveness of traffic signs depends on its feature to communicate the message to the drivers and emoticon is the other one of the message to the other. As well as traffic signs. Traffic signs are parts of road equipment in the form of symbols, letters, numbers, sentences, or a combination of them which serve as a warning, regulatory, command or guide for road users. Warning signs are signs used to express a warning of hazard or dangerous places on the road ahead of the road users. Regulatory signs are signs used to specify any actions which road users are not allowed to do. Command signs are signs used to express a command which must be done by road users. Guide signs are signs used to provide directions, roads, situations, places, facility arrangements and the like to road users [3].

The article aims to know the opinion of people against the designs of emoticon symbol that applied to traffic signs especially the traffic warning signs. Then conducted a study of three designs tested to the adult peoples. The sample designs to alert the driver about people distraction driving behavior that does not give priority to traffic safety, one sample design to give warning to drivers to always concentrate on the traffic by not operate the cellphone.

\section{MATERIAL AND METHODS}

The traffic signs that made by emoticon symbols is the main material of this research. There is a need for some creativity to make the emoticon designs to be traffic signs because traffic signs generally can achieve its effective function based on numerous factors, including designs and non-design factors. The design factors mainly focus on the drivers who see the traffic signs, that consist of the drivers' capability to understand the meaning of the traffic signs, its named driver comprehension [4], [5], [6], [7], [8], [9], [10]; the drivers' notice to the traffic signs, its named traffic signs conspicuity [11], [12] the drivers' capability to memorize the traffic signs, its named traffic signs learnability; the relevance of the condition to the drivers' experience that may generate the signs; and the disparity of the traffic sign and the other ones, its named traffic signs distinctiveness [5].

\section{A. Material Designs Description}

The description of the material design and the meaning of the traffic sign design can be shown in Figure 1. Design A is a distract driver because of the influence of alcohol, depicted by sleeping eyes, small smile with unsymmetrical lips, oblique position and unstable way of driving. This implies that the driver is in a fly and tends to be careless, supposing able to do anything without considering and realize others' safety. This kind of drivers tends to drive a zig-zag or have no concern for the safe space and tends to break the traffic. Design B is a distract 
driver because influenced by reading or text to operate the cell-phone, depicted by the closed mouth with a small smile and focus in texting the screen of cell-phone. This kind of drivers tends to have no awareness or simply careless to other vehicles and traffic since they do not realize that this kind of action can be dangerous either for them or others. Design $\mathrm{C}$ is a distract driver, depicted by too much talking, discussing or debate with the other passenger, lost concentrate, lost control and emotion. Driver too focus on the dialogue with other passenger and has no awareness for the danger that he probably cause either toward himself or others.

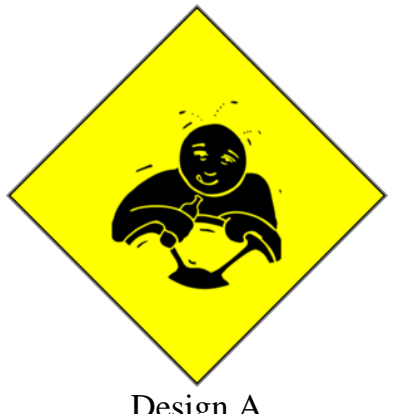

Design A

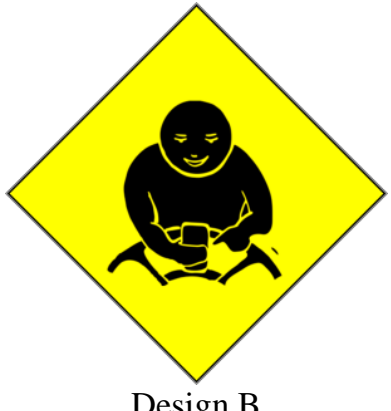

Design B

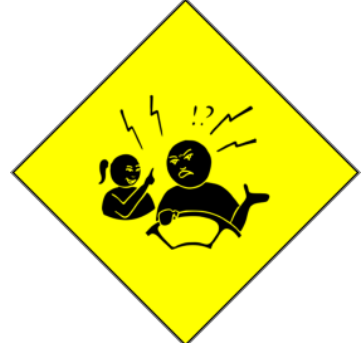

Design C

Figure 1. Traffic signs design from the emoticon symbol

\section{B. Method}

There are 140 participants in research that have owned driving licenses, 92 male and 48 female by the age interval between 17 and 64 years old. Scrutinizing the respondents' notions toward 3 designs of traffic signs of the emoticon symbols uses self report technique of likert scale.

A principle basic to Likert scale measurement methodology is that scores yielded by a Likert scale are composite (summated) scores derived from an individual's responses to the multiple items on the level scale of comprehension, conspicuity, learnability and relevance toward the signs of $\operatorname{design} \mathrm{A}$, design $\mathrm{B}$, and designs $\mathrm{C}$.

The participants' notions for the comprehension toward the traffic signs design classified into 5 kinds of scoring, in which 5 means as "it is easy to understand", 4 means as "quite easy to understand", 3 means as "enough easy to understood", 2 means as "less easy to understand" and 1 means as "very not easy to understand". The respondents' notions for the conspicuity toward the traffic warning signs of aggressive driver, anger driver, distract driver, and fatigue driver is classified into 5 kinds of scoring, in which 5 means as "very interesting", 4 means as "enough to attract attention", 3 means as "to attract attention", 2 means as "less draw attention" and 1 means as "very inconspicuous". The respondents' notions for the learnability toward the traffic warning signs of aggressive driver, anger driver, distract driver, and fatigue driver is classified into 5 kinds of scoring, in which 5 means as "it's easy to remember", 4 means as "quite easy to remember", 3 means as "enough easy to remember", 2 means as "less easy to remember", and 1 means as "difficult to remember". The respondents' notions for the relevance toward the distract driver, is classified into 5 kinds of scoring, in which 5 means as "very often", 4 means as "often enough", 3 means as "somewhat frequently", 2 means as "sometimes", and 1 means as "never".

\section{RESULTS AND DISCUSSION}

A. Results

Reliability describes the accuracy of measurement. The reliability of a test score is frequently described as the dependability, consistency, or stability of the score produced by a particular instrument, which in this case is a summated total score or a summated subscale score derived from a Likert-type scale. Reliability statistics for 12 variables gotten from 4 kinds of tested designs show the value of Cronbach Alpha equals to 0.872. This means that the values from every variable stated as reliable.

Table 1 and Figure 2 stated the result of 3 kinds of traffic signs of emoticon symbols to participants. The resulted show the comprehension toward distract driver because influenced of alcohol equals to 3.90 (quite easy and enough to understand), distract driver because influenced of read or text to operate the cell-phone equals to 3.81 (quite easy and enough to understand), and distract driver because too much talking with the other passenger equals to 3.65 (quite easy and enough to understand). 
TABLE 1. DESCRIPTIVE STATISTIC

\begin{tabular}{|c|c|c|c|c|c|c|c|c|c|c|c|c|c|}
\hline & & 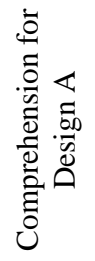 & 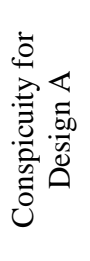 & 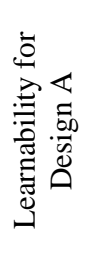 & 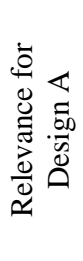 & 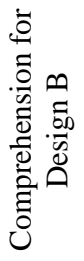 & 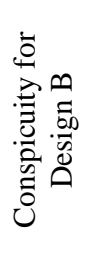 & 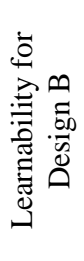 & 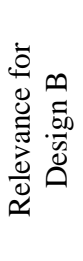 & 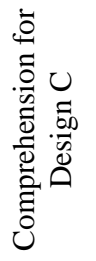 & 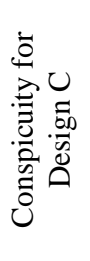 & 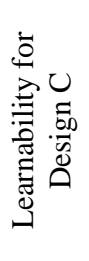 & 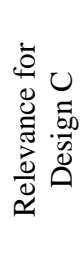 \\
\hline \multirow{3}{*}{$\mathrm{N}$} & Valid & 140 & 140 & 140 & 140 & 140 & 140 & 140 & 140 & 140 & 140 & 140 & 140 \\
\hline & Missing & 0 & 0 & 0 & 0 & 0 & 0 & 0 & 0 & 0 & 0 & 0 & 0 \\
\hline & Mean & 3.90 & 3.69 & 3.78 & 1.31 & 3.81 & 3.63 & 3.74 & 1.85 & 3.65 & 3.56 & 3.50 & 2.03 \\
\hline \multicolumn{2}{|c|}{ Std. Deviation } & 1.12 & 1.04 & 1.07 & 0.88 & 1.12 & 1.04 & 0.97 & 1.17 & 1.09 & 1.06 & 1.02 & 1.22 \\
\hline
\end{tabular}
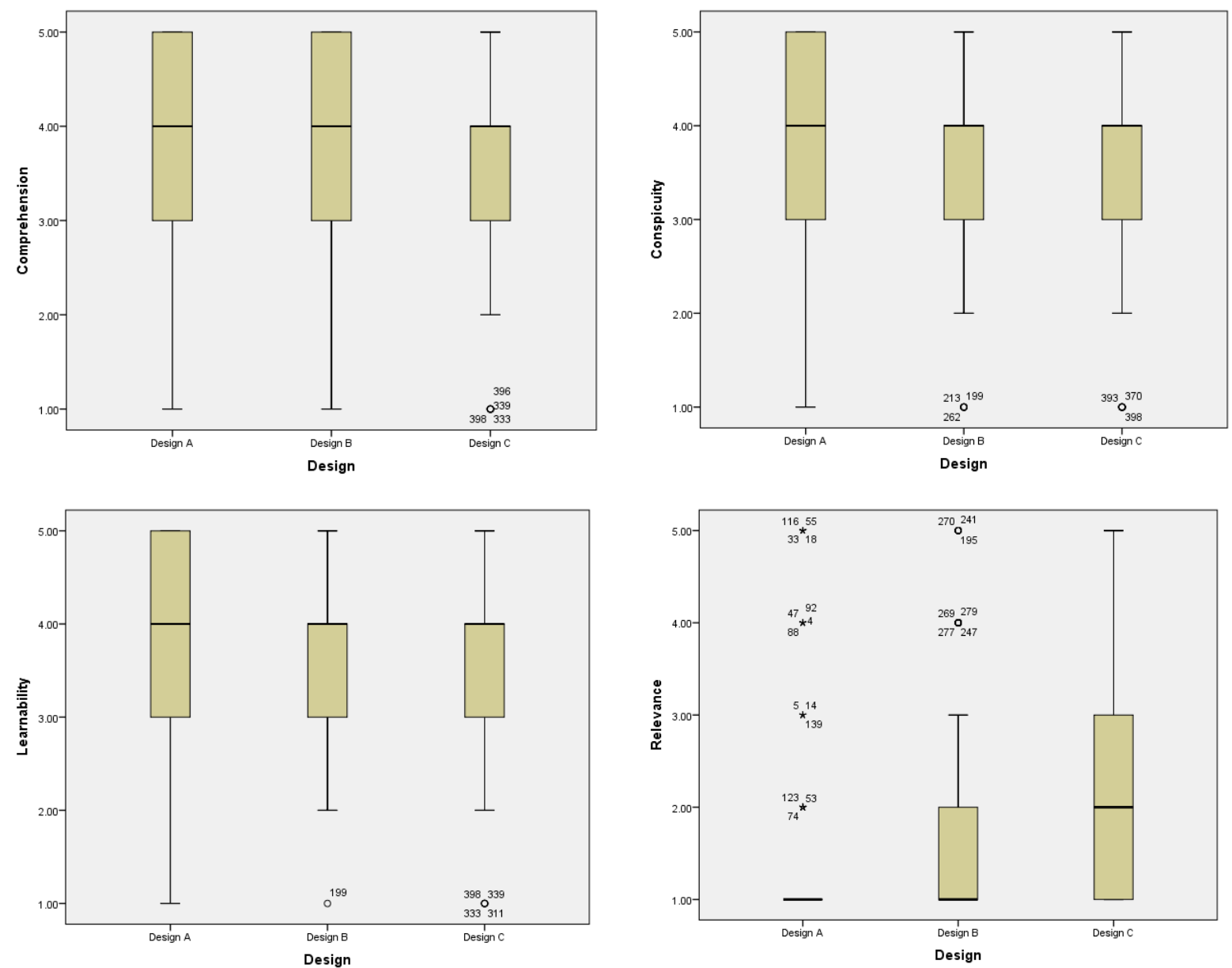

Figure 2. Comprehension, conspicuity, learnability, and relevance stem and leaf plot for design A, design B, and design C

The conspicuity toward distract driver because influenced of alcohol equals to 3.69 (quite easy and enough to attract attention), distract driver because influenced of read or text to operate the cell-phone equals to 3.74 (quite easy and enough to attract attention), and distract driver because too much talking with the other passenger equals to 3.56 (quite easy and enough to attract attention).

The learnability toward distract driver because influenced of alcohol equals to 3.78 (quite easy and enough to remember), distract driver because influenced of read or text to operate the cell-phone equals to 3.74 (quite easy and enough to remember), and distract driver because too much talking with the other passenger equals 3.50 (quite easy and enough to remember).

The relevance toward the sign of distract driver because influenced of alcohol equals to 1.31 (never and sometimes), distract driver because influenced of reading or text to operate the cell-phone equals to 1.85 (never and 
sometimes), and distract driver because too much talking with the other passenger equals to 2.03 (sometimes).

\section{B. Discussion}

The proper designs of traffic signs come from the drivers' notions toward the meaning represented by the sign itself [9], interest of the drivers or conspicuity [6], [11], [12], [13], [14] simplicity to remember or learnability, correlation toward the drivers' experiences or relevance.

The statistical data derived from the respondents' notions show that 3 traffic warning signs have the median score equals 3.50 until 3.90 from the highest score 5.00 toward the comprehension, conspicuity, and learnability. This shows that drivers commonly state that emoticon traffic signs are quite easy and enough to understand for the comprehension, quite easy and enough to attract attention for the conspicuity and quite easy and enough to remember for the learnability. The emoticon of warning traffic signs show the score 1.31 to 2.03 for the highest scores of 5.00. It means the relevance conditions represented that designs are never or sometimes relevance with experienced by the drivers.

\section{CONCLUSION}

Emoticon symbols used for traffic signs can be an innovative breakthrough in communicating the instructional information to the drivers, particularly those who experience the message represented by the emoticon symbols. They have better for comprehension, conspicuity, learnability, and relevance to the traffic and behavior condition for a driver. The traffic signs can be understood broadly, mainly by those who are illiterate or problematic in linguistic.

\section{ACKNOWLEDGMENT}

Our thanks my daughter Hana and my son Shidqi for support to entry data and also to my surveyor team. This research did not receive any specific grant from funding agencies in the public, commercial, or not-for-profit sectors.

\section{REFERENCES}

[1] Azuma Junichi and Ebner Martin. A Stylistic Analysis of Graphic Emoticons: Can they be Candidates for a Universal Visual Language of the Future?, Proceeding of World Conference on Educational Media, Hypermedia and Telecommunications (EDMedia), 2008, pp. 972-977, 2008.

[2] Rezabek, L. L., and Cochenour, J. J. Visual cues in computermediated communication: Supplementing text with emoticons. Journal of Visual Literacy, 18, pp. 201-215, 1998.

[3] Ministry of Transportation Republic of Indonesia, Ministerial Regulation on Traffic Signs No. PM 13 Tahun 2014, 2014.

[4] P.M., Pietrucha M.T., and Meeker D., Effects of font and capitalization on legibility of guide signs. Transportation Research Record 1605, TRB, National Research Council, Washington, DC, 1997, pp. 73-79, 1997.

[5] Swanson, H.A., Kline DW., and Dewar R.E., Guidelines for Traffic Sign Symbols, ITE Journal, May 1997, pp 30-35, 1997.

[6] Lesch, M.F., Comprehension and memory for warning symbols: Age-related differences and impact of training, Journal of Safety Research 34, pp 495-505, 2003

[7] Al-Kaisy, A, Static warning signs for occasional hazards: a synthesis of research and practice, Western Transportation Institute Montana State University Bozeman, Montana, 2006

[8] Razzak, A. and Hasan T., Motorist understanding of traffic signs: a study in Dhaka city, Journal of Civil Engineering (IEB), 38 (1), pp 17-29, 2010

[9] Wogalter, M.S., Kalsher, M.J., Frederick, L.J., Magurno, A.B., and Brewster. Hazard level perceptions of warning components and configuration, International Journal of Cognitive Ergonomics, 2(1-2), pp 123-143, 1998.

[10] Al-Madani, H. and Al-Janahi, A. R. "Role of drivers' personal characteristics in understanding traffic sign symbols", Accident Analysis and Prevention (34): pp 185-196, 2002.

[11] Dewar, R., Kline, D., Scheiber, F., and Swanson A., Symbol signing design for older drivers, Publication No. FHWA-RD-94069, Federal Highway Administration, U.S. Department of Transportation, 1997.

[12] Koppa, Human Factors Chapter 3, Publications Research Operations, www.fhwa.dot.gov., 2010-12-06, 2010

[13] Annie W.Y. Ng and CAlan H.S. Chan, Cognitive Design Features on Traffic Signs, Engineering Letters, 14:1, EL_14_1_3 (Advance online publication: 12 February 2007), 2007.

[14] Laughery, K.R., dan Wogalter, M.S. A three-stage model summarizes product warning and environmental sign research, Safety Science 61, Elsevier Ltd., pp: 3-10, 2014. 